\title{
3D CBCT Evaluation of Condụle Position in Skeletal Class I \& Class III Growing Subjects
}

\author{
Dr Rajeev Kumar Mishra,' Dr Om Prakash Kharbanda,2 Dr Rajiv Balachandran³ \\ 'Lecturer, Dept of Orthodontics, College of Medical Sciences, Bharatpur, Nepal \\ ${ }^{2}$ Prof, ${ }^{3}$ Research Fellow, Dept of Orthodontics, Centre for Dental Education \& Research, \\ All India Institute of Medical Sciences, New Delhi, India
}

Correspondence: Dr Rajeev Kumar Mishra; Email: mishra.rkm84@gmail.com

\section{ABSTRACT}

Introduction: Evaluation of temporo-mandibular joint (TMJ) anatomy and function is an essential part of orthodontic diagnosis and treatment planning. It has been hypothesized that dental and skeletal malocclusions alter the functional loading of TMJ which can affect joint morphology.

Objective: Three dimensional (3D) evaluation of condylar position using CBCT in skeletal Class I and Class III growing subjects.

Materials \& Method: CBCT images of ten growing skeletal Class I \& ten Class III patients in the age range of 7-14 years were analyzed. 3D condylar position were evaluated representing antero-posterior, vertical, laterolateral position of condyle, axial condylar angle and coronal condylar angles which were measured in axial, coronal and sagittal sections using Dolphin Imaging software. Antero-posterior and vertical difference of right and left condyle were measured in axial and coronal sections respectively.

Result: Paired t-Test revealed no significant difference between right and left sides of condyle in skeletal Class I as well as Class III subjects. Independent t-test and Mann-Whitney U test showed no significant difference between position of condyle in Class I and Class III subjects.

Conclusion: 3D CBCT analysis shows no significant difference in condylar position of skeletal Class I and Class III subjects.

Keywords: $\mathrm{CBCT}$, condyle position, skeletal growth pattern

\section{INTRODUCTION}

For majority of patients undergoing orthodontic therapy, esthetics is the primary concern however the long term success of orthodontic therapy can only be ascertained by ensuring optimal functional efficiency of the masticatory apparatus. The relationship between malocclusion pattern and temporo-mandibular joint (TMJ) problems are not clear and so is the relationship between orthodontic treatment and TMJ disorders. ${ }^{1}$ Most of the previous studies ${ }^{2-4}$ suggest that the incidence of TMJ disorders between subjects who have received orthodontic therapy and those who have not were similar but orthodontist should always be aware of the fact that nearly all orthodontic therapy alters patients' existing occlusion and may predispose the patient to TMJ disorders. Hence knowledge of normal anatomy and its variations are essential for orthodontist. The effect of function on form is well documented in orthodontic literature. The form of temporo-mandibular joint can be affected by various anatomical and pathological factors. Facial anatomical factors like growth pattern, dental and skeletal malocclusion can affect the morphology of TMJ by altering the loading pattern of the joint. ${ }^{5,6} \mathrm{TMJ}$ morphology of Class I and Class III subjects has been compared in few studies but the findings of these studies are not uniform. ${ }^{5,7-9}$ Some studies have reported no significant difference between the condylar position in Class I and Class III subjects, ${ }^{7,8}$ while others have reported the difference. ${ }^{5,9}$ These discrepancies might be due to differences in measuring technique and parameters used to assess the condylar position. Various two dimensional radiographic views like panoramic radiograph, TMJ radiograph, cephalograms have been used to asses condylar position but the overlapping of surrounding structures over the TMJ limit the accuracy of these methods. ${ }^{5}$ 3D imaging procedures like conventional CT had also been used, ${ }^{10,11}$ but the risk of high radiation exposure has limited the use of this method. CВCT has emerged as a useful imaging technique owing to significantly low radiation exposure as compared to conventional CT and high quality of 3D images; ${ }^{12}$ however very few studies, till date have used CBCT data to evaluate condylar position 


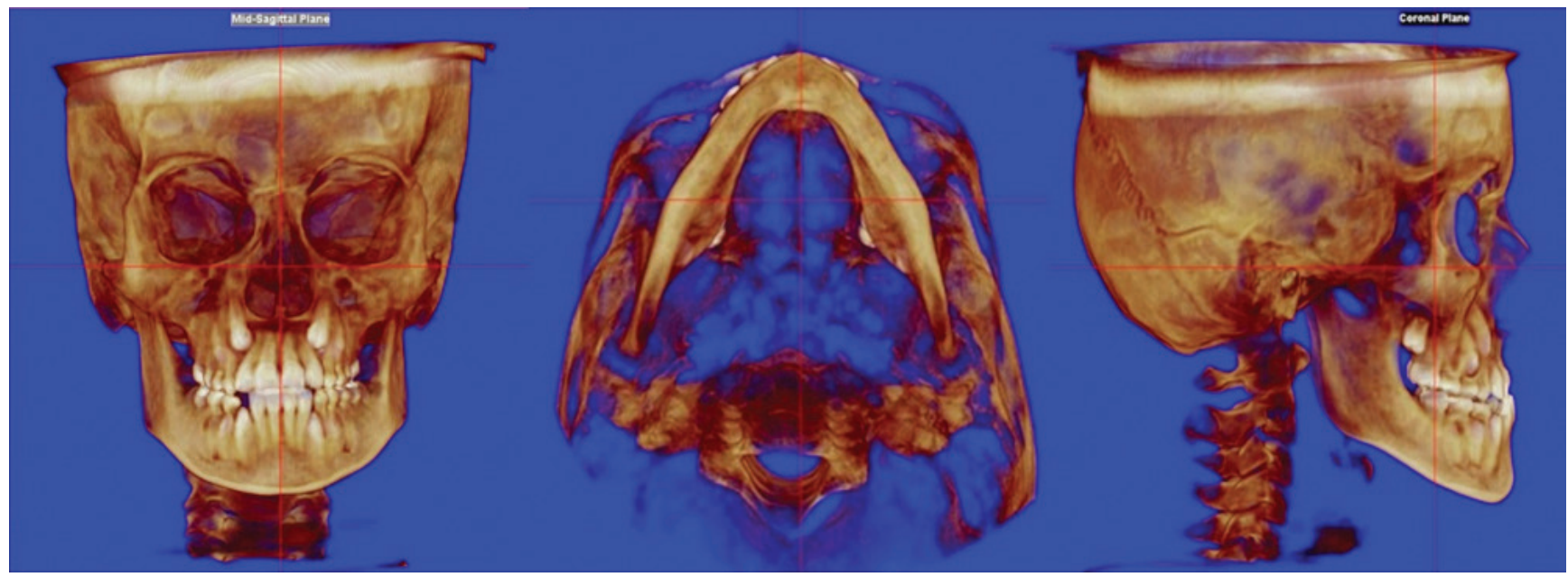

Figure 1: $C B C T$ Image orientation

\section{MATERIALS AND METHOD}

The study was conducted at a university orthodontic department. Cone beam computed tomography (CBCT) image were retrieved from department archives of the patients in the age range of 7-14 years. The DICOM (Digital Imaging and Communications in Medicine) images were evaluated with Dolphin imaging software Version 11.7 (Dolphin Imaging \& Management Solutions, Chatsworth, California). These images were rendered into volumetric images and reconstructed sagittal, axial, coronal slices and the 3D models were obtained. The 3D images were oriented such that the mid-sagittal plane passed through the skeletal midline, the axial plane showed the FH plane (right porion to right orbitale), and the coronal plane passed through the furcation of the right maxillary first molar (Figure 1). After orienting the images, lateral cephalograms were obtained from the CBCT images using ray-sum feature of the software. Subjects were classified on the basis of ANB angle. Ten Class I subjects (seven male, three female) and ten Class III subjects (five male, five female) were selected (Table 1). The inclusion criteria were: $\mathrm{ANB}<0^{\circ}$ for Class III and $0-4^{\circ}$ for Class I, no other craniofacial anomalies, no symptoms or history of TMJ disorders, no history of previous orthodontic treatment, and average growth pattern (FMA: $17^{\circ}-28^{\circ}$ ). Evaluation of condylar position was based on the methodology described by Melgaco et $\mathrm{al}^{13}$ and modifications suggested by Balachandran et al. ${ }^{14}$ All measurements were done by principal investigator.
Table 1: Demographic features of study sample

\begin{tabular}{|l|c|c|c|}
\hline & Number & Mean Age & Mean ANB \\
\hline Class I & $10(7 \mathrm{M} / 3 \mathrm{~F})$ & $10.8 \pm 1.61$ & $1.4 \pm 0.90$ \\
\hline Class III & $10(5 \mathrm{M} / 5 \mathrm{~F})$ & $10.8 \pm 1.4$ & $-2.3 \pm 1.210$ \\
\hline
\end{tabular}

The landmarks used were as follows (Figure 2):

1. Centre of condyle $(\mathrm{CC})$ : Intersection of lines representing largest anteroposterior and mediolateral widths of condyle, identified in axial slice.

2. External acoustic meatus (EAM): The most external point in the posterior wall of external acoustic meatus, identified in axial slice.

3. Laterosuperior condylar landmarks (LSC): The point at the intersection of tangent to the most superior and lateral part of condyle, identified in coronal slice.

After landmark identification, digitization was done on the software to measure following parameters:

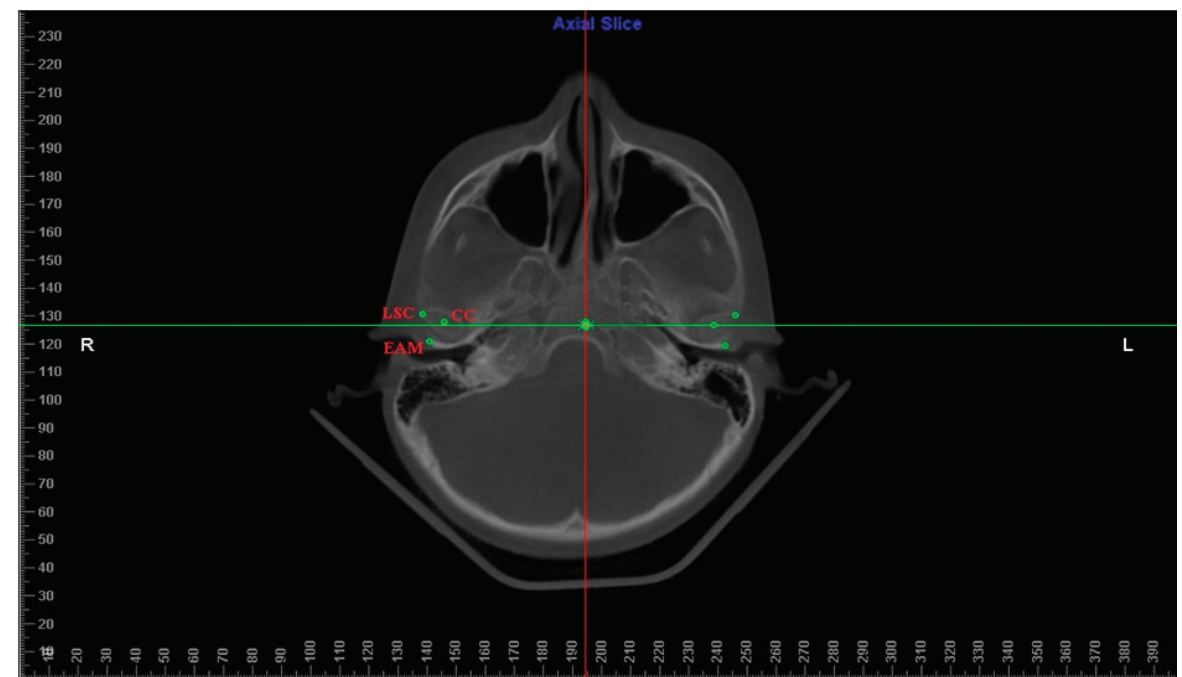

Figure 2: Axial slice showing landmarks 


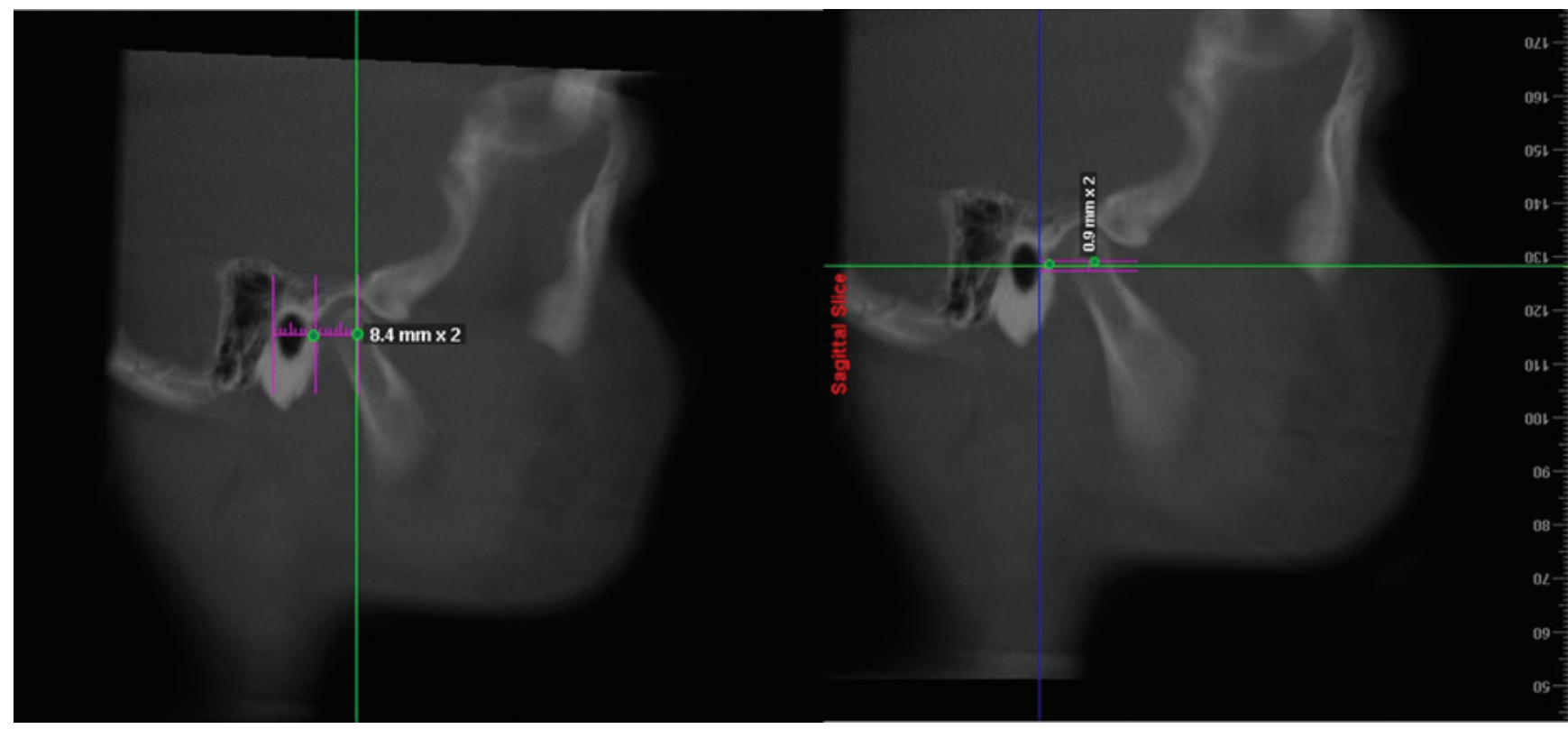

Figure 3: Sagittal section measurements

1. Sagittal section measurements (Figure 3):

a. Anterioposterior position of condyle (APC): Horizontal distance between the external acoustic meatus and centre of condyle

b. Vertical Position of condyle (VPC): Vertical distance between EAM and centre of condyle.

2. Axial section measurement (Figure 4):

a. Axial condylar angle (ACA): Angle formed between the line connecting centre of condyle and laterosuperior point of condyle and midsagittal plane (MSP)

b. Laterolateral position of condyle (LLPC): Distance between centre of condyle and MSP

c. Antero-posterior difference of condyle (APDC): Distance between orthogonal projection of left and right condylar center on MSP as measured.

3. Coronal section measurements (Figure 5): a. Coronal condylar angle (CCA): Angle formed between the MSP and line connecting LSC and centre of condyle

b. Vertical difference of condyles (VDC): Vertical distance between the orthogonal projection of left and right center of condyle on the MSP.

Each measurement was done separately on right and left sides. Measurements were repeated twice after one week interval in ten cases and intra-class correlation coefficient (ICC) was used to determine the reliability of measurement. The statistical analysis was done using SPSS software version 17. Kolmogorov-Smirnov test was used to determine the normalcy of data distribution. For parameters with normal distribution, paired t-test was applied for comparison between left and right sides of the subjects while independent t-test was used to compare between Class I and Class III subjects. Mann-Whitney $U$ test was used to compare between Class I and III for parameters which were not normally distributed. The level of significance was set at $p<0.05$.

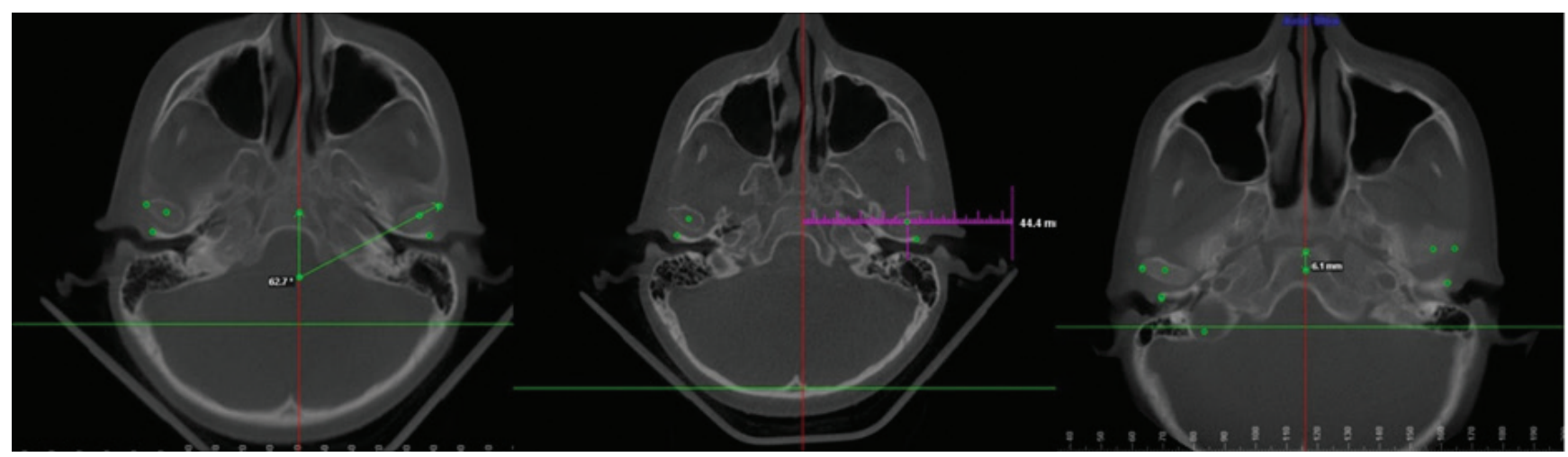

Figure 4: Axial Section measurement 


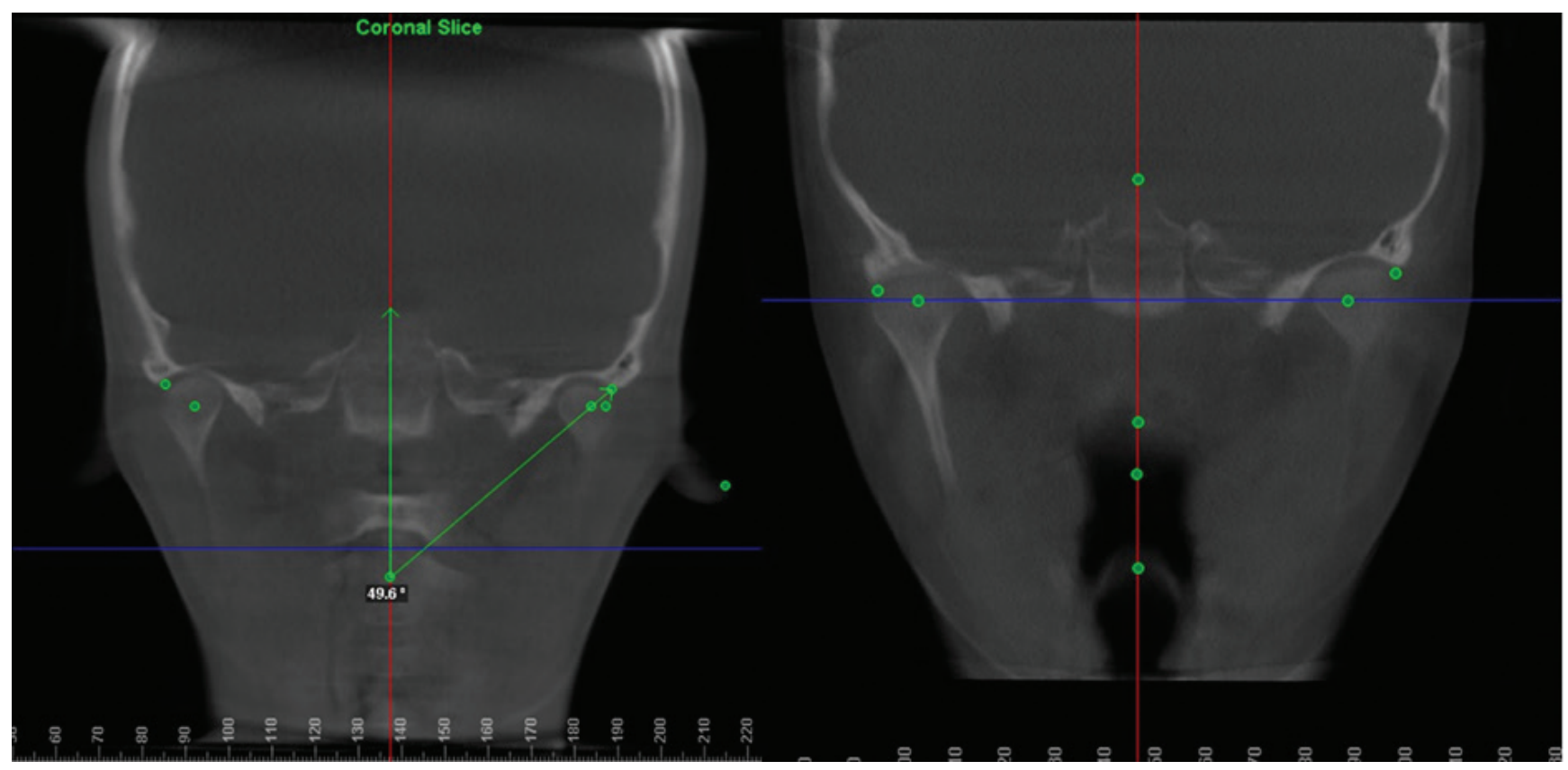

Figure 5: Coronal Section measurement

\section{RESULT}

Kolmogrov-Smirnov test showed that the data was normally distributed except for three measurements viz: APDC, VDC and VPC. ICC values were higher than 0.9 showing high reliability of measurement for all parameters. Paired t-test showed no significant difference between right and left condyle position either in Class I or Class III subjects (Table2). Centre of condyle was more anteriorly placed in Class I subjects as compared to Class III subject but condyle was more anteriorly inclined in Class III subjects. The inter- condylar distance was greater for Class III subjects as compared to Class I subjects. In coronal section parameters- medio-lateral inclination as indicated by CCA was nearly same for both Class I and Class III subjects. Antero-posterior difference between right and left condyle was greater in Class I subjects as compared to Class III. Vertical difference between right and left condyle was negligible and nearly equal for both classes. The difference between condyle position of skeletal Class I and Class III subjects was not statistically significant when compared in axial, coronal and sagittal planes.

Table 2: Comparison between left and right side condyle position

\begin{tabular}{|c|c|c|c|c|c|c|}
\hline & \multicolumn{3}{|c|}{ Class I } & \multicolumn{3}{|c|}{ Mean ANB } \\
\hline & Right (Mean \pm SD) & Left (Mean士SD) & $p$-Value & Right (Mean \pm SD) & Left (Mean士SD) & $p$-Value \\
\hline $\mathrm{ACA}$ & $84.4 \pm 5.02$ & $83.9 \pm 5.1$ & 0.63 & $81.6 \pm 6.4$ & $78.9 \pm 8.7$ & 0.06 \\
\hline LLPC & $43.5 \pm 2.2$ & $43.1 \pm 3.0$ & 0.70 & $46.7 \pm 4.8$ & $46.9 \pm 6.21$ & 0.73 \\
\hline CCA & $58.7 \pm 4.2$ & $60.7 \pm 6.5$ & 0.12 & $60.4 \pm 6.3$ & $58.8 \pm 5.4$ & 0.57 \\
\hline APC & $8.5 \pm 1.4$ & $8.4 \pm 1.9$ & 0.75 & $7.8 \pm 1.0$ & $7.1 \pm 0.9$ & 0.09 \\
\hline VPC & 0.0 & 0.20 & 0.34 & 0.0 & 0.26 & 0.34 \\
\hline
\end{tabular}

Table 3: Independent T-test for comparison of Class I \& Class III condyle position

\begin{tabular}{|l|c|c|c|}
\hline & Class I & Class III & p-Value \\
\hline ACA & $84.1 \pm 4.9$ & $80.3 \pm 7.3$ & 0.19 \\
\hline LLPC & $43.3 \pm 2.2$ & $46.8 \pm 5.4$ & 0.09 \\
\hline CCA & $119.0 \pm 10.6$ & $119.2 \pm 8.2$ & 0.95 \\
\hline APC & $8.4 \pm 1.5$ & $7.5 \pm 0.83$ & 0.13 \\
\hline
\end{tabular}


Table 4: Comparison of Class I and Class III condyle position

\begin{tabular}{|c|c|c|c|c|c|}
\hline & \multicolumn{2}{|c|}{ Class I } & \multicolumn{2}{|c|}{ Mean ANB } & \multirow{2}{*}{$p$-Value } \\
\hline & Median & Range & Median & Range & \\
\hline APDC & 1.6 & $0-3.2$ & 1.4 & $0-5.9$ & 0.49 \\
\hline VDC & 0 & $0-1.8$ & 0.5 & $0-1.7$ & 0.78 \\
\hline VPC & 0 & $0-0.95$ & 0 & $0-1.3$ & 1.00 \\
\hline
\end{tabular}

(ACA: axial condylar angle, LLPC: laterolateral position of condyle, CCA: coronal condylar angle, APC: antero-posterior position of condyle, VPC: vertical position of condyle, APDC: antero-posterior difference of condyle, VDC: vertical difference of condyle)

\section{DISCUSSION}

In the present study, ANB angle was used to classify subjects in two skeletal groups. Despite its shortcomings ANB angle is most commonly used to differentiate sagittal skeletal patterns. ${ }^{15}$ The accuracy and reliability ofDolphin software forlinear and angularmeasurements has been established by previous studies. ${ }^{16}$ CBCT images are accurate and provide detailed images with good spatial resolution for assessing TMJ while the exposure is very low as compared to conventional CT. 5 .9 Relationship between occlusion and TMJ morphology has been reported by several previous studies, ${ }^{17-20}$ however very few studies have compared mandibular condyle position between skeletal Class I and Class ||| subjects., ${ }^{5-9}$ In some studies, lateral cephalograms were used to evaluate the position of condyle which cannot be considered reliable because of the superimposition of surrounding structures like petrous temporal bone, mastoid process and articular eminence; making visualization of condyle difficult. 5,8 In this study we have modified the methodology of Melgaco et $\mathrm{al}^{13}$ in two ways. First, the head orientation was not reestablished after land mark orientation. Second, a large slice thickness was used when two landmarks were not visible in single slice. This was true mainly for measurement of coronal condylar angle. As suggested by Balachandran et $a l,{ }^{14}$ this could increase the chances of error but we could not find any suitable alternate method.

Marrieta et $a l^{5}$ reported some spatial difference in condylar position between Class I, Class II and Class III groups. They found that condyle in Class III was more superiorly and anteriorly placed as compared to Class I and the difference was statistically significant. Previous studies showed variation in condyle position in subjects with hyperdivergent and hypodivergent subjects. ${ }^{21}$ In our study all subjects had average growth pattern, hence the findings could not be directly compared.

Alhammadi et $a l^{9}$ reported significant difference between vertical position and antero-posterior inclination in Class I and Class III subjects. In their study anteroposterior inclination of condyle was higher in Class III subjects while centre of condyle was more anteriorly placed in Class I subjects. These findings are similar to our study. The intercondylar distance was higher in Class I subjects as compared to Class III subjects which is in contrast to our findings. This disparity may be due to the difference in growth status of study sample and difference in landmark measurement parameters between the studies.

The authors could find only three similar previous studies and all those studies have differences in landmark identification and measurement methodology. No previous studies have used methodology similar to ours, thus direct comparison of these studies are not possible.

In the present study, the subjects were in growing stage, hence the position of condyle may also change with aging. The power of the study is inadequate because of small sample size. All the CBCT images were retrieved from archives and no image was obtained for purpose of this study.

\section{CONCLUSION}

Three dimensional CBCT analyses revealed no difference in condylar position between skeletal Class I and Class III growing subjects.

\section{OJN}




\section{REFERENCES}

1. Okeson JP, Ikeda K. Orthodontic therapy and the temporomandibular disorder patient. In Graber TM, Vanarsdall VK. Orthodontics Current Principles and Technique. Elsevier 5th Edition, pp. 175-214.

2. Sadowsky C, Polson AM. Temporomandibular disorders and functional occlusion after orthodontic treatment: results of two long-term studies, Am J Orthod. 1984; 86:386-90.

3. Kim MR, Graber TM, Viana MA. Orthodontics and temporomandibular disorder: A meta-analysis, Am J Orthod Dentofac Orthop. 2002; $121: 438-46$.

4. How CK: Orthodontic treatment has little to do with temporomandibular disorders. Evid Based Dent. 2004; 5:75.

5. Arieta-Miranda JM, Silva-Valencia M, Flores-Mir C, Paredes-Sampen NA, Arriola-Guillen LE. Spatial analysis of condyle position according to sagittal skeletal relationship, assessed by CBCT. Prog Orthod. 2013; 14:36.

6. Ueki K, Nakagawa K, Takatsuka S, Yamamoto E, Laskin DM. Comparison of the stress direction on the TMJ in patients with Class I, II, and III skeletal relationships. Orthod Craniofac Res. 2008; 11 (1):43-50.

7. Hegde SS, Revankar AV, Patil AK. Evaluating condylar position in different skeletal malocclusion patterns: A cephalometric study. APOS Trends Orthod. 2015; 5:111-5.

8. Paknahad M, Shahidi S, Abbaszade H. Correlation between condylar position and different sagittal skeletal facial types. J Orofac Orthop. 2016; 77(5):350-6.

9. Alhammadi MS, Fayed MS, Labib A. Three-dimensional assessment of temporomandibular joints in skeletal Class I, Class II, and Class III malocclusions: CBCT analysis. J World Fed Orthod. 2016; 5(3):80-6.

10. Katsavrias EG. Condyle and fossa shape in Class II and Class III skeletal patterns: A morphometric tomographic study. Am J Orthod Dentofac Orthop. 2005; 128(3):337-46

11. Rodrigues AF, Fraga MR, Vitral RW. Computed tomography evaluation of the TMJ in Class II division 1 and Class III malocclusion patients: Condylar symmetry and condyle-fossa relationship. Am J Orthod Dentofac Orthop. 2009; 136:199-206.

12. Pauwels R, Beinsberger J, Collaert B, Theodorakou C, Rogers J, Walker A. Effective dose range for dental cone beam computed tomography scanners. Eur J Radiol. 2012; 81 (2):267-71.

13. Melgaco CA, Columbano NJ, Jurach EM, Nojima MC, Nojima LI. Immediate changes in condylar position after rapid maxillary expansion. Am J Orthod Dentofac Orthop. 2014; 145(6):771-9.

14. Balachandran R, Mishra RK, Kharbanda OP. Postexpansion changes related to condylar position. Am J Orthod Dentofac Orthop. 2015; 148(1):9-10

15. Hussels W, Nanda RS. Clinical application of a method to correct angle ANB for geometric effects. Am J Orthod Dentofac Orthop. 1987; 92(6):506-10

16. Fernandes TMF, Adamczyk J, Poleti ML, Henriques JJC, Friedland B, Garib DG. Comparison between 3D volumetric rendering and multiplanar slices on the reliability of linear measurements on CBCT images: An in vitro study. J Appl Oral Sci. $2015 ; 23(1): 56-63$.

17. Rodrigues AF, Fraga MR, Vitral RW. Computed tomography evaluation of the temporomandibular joint in Class II division 1 and Class III malocclusion patients: condylar symmetry and condyle-fossa relationship. Am J Orthod Dentofac Orthop. 2009; 136:199-206.

18. Katsavrias EG. Condyle and fossa shape in Class II and Class III skeletal patterns: A morphometric tomographic study. Am J Orthod Dentofac Orthop. 2005; 128(3):337-46.

19. Vitral RWF, deSouza TC, Fraga MR, deOliveira RSMF, Tanaka OM. Computed tomography evaluation of temporomandibular join alterations in patients with Class II division 1 subdivision malocclusions: Condyle-fossa relationship. Am J Orthod Dentofac Orthop. 2004; 126(1):48-52.

20. Seren E, Akan H, Toller MO, Akyar S. An evaluation of the condylar position of the temporomandibular joint by computerized tomography in Class III malocclusions: a preliminary study. Am J Orthod Dentofac Orthop. 1994; 105:483-8.

21. Girardot RA Jr. Comparison of condylar position in hyperdivergent and hypodivergent facial skeletal types. Angle Orthod. 2001; 71 (4):2406. 